\title{
Analyzing the Potential of Flipped Classroom in ESL Teaching
}

\author{
http://dx.doi.org/10.3991/ijet.v11i03.5309 \\ O.S. Kvashnina, E.A. Martynko \\ National Research Tomsk Polytechnic University, Tomsk, Russia
}

\begin{abstract}
Despite the buzz around the flipped or inverted classroom as a new trend in educational practice and research, there is a limited number of studies on its effectiveness in English as a Second Language (ESL) teaching. This paper aims at contributing to the field of flipped classroom research by briefly examining and analyzing the outcomes of the experiment conducted at the Tomsk Polytechnic University within the course of English for Engineering. Outlining several challenges, the authors conclude on the significant benefits of the flipped classroom in ESL teaching including an increase in students' overall performance on the course, enhancement of students' motivation and improvement of their autonomous learning skills.
\end{abstract}

Index terms-ESL teaching, flipped classroom, blended learning, e-course, English for Engineering

\section{INTRODUCTION}

It is hard to disregard the increasing interest to the idea of the flipped classroom first being widely embraced and successfully adopted by the American and European pedagogical communities and now being more often considered in the studies of the Asian universities. The method is even mentioned as one of the "important developments in educational technology for higher education" in the Horizon Report for Higher Education in 2015 [1] and has been the focus of many recent publications.

The model of the flipped classroom refers to a larger pedagogical movement that comprises the vast notion of blended learning, inquiry-based learning, and other methods and tools that are commonly expected to be flexible, easily accessible, interactive, and, what is more important, more engaging for students. The idea behind the flipped classroom method is to employ the technology to present the "teaching part", i.e. the part aimed at presenting and explaining the information under study, and to focus more intensely on higher cognitive, group-based, project-based learning where students take part in customized discussions to solve any challenges and share their ideas in traditional classroom leading to a deeper understanding of the subject [1]. Thus, instead of using the classroom time for the "information delivery stage", the teacher can ask students to watch a recorded video lecture or talk, listen to a podcast, read an article, etc. by accessing the online tools and/or resources prior to the traditional class. After the class, students can proceed with their discussions via forums or chats; demonstrate their knowledge and skills through the completion of final assessment tasks, projects, or online tests.

In our paper we would like to analyze the relevance and potential of the flipped classroom in ESL teaching based on the experience of the Tomsk Polytechnic University.

\section{RELEVANCE TO ESL TEACHING}

Essentially, the flipped classroom is an approach to organizing the learning process and the learning content. If we consider Bloom's revised taxonomy (Figure 1) [2], students are first organized to deal online with the lower levels of cognitive work (recall relevant background knowledge, gain new knowledge and check its comprehension via tests). Then, in brick-and-mortar environment they are supposed to focus on the higher forms of cognitive work including application, analysis, synthesis, evaluation, and creation with the support of their peers and under the guidance of the subject instructor.

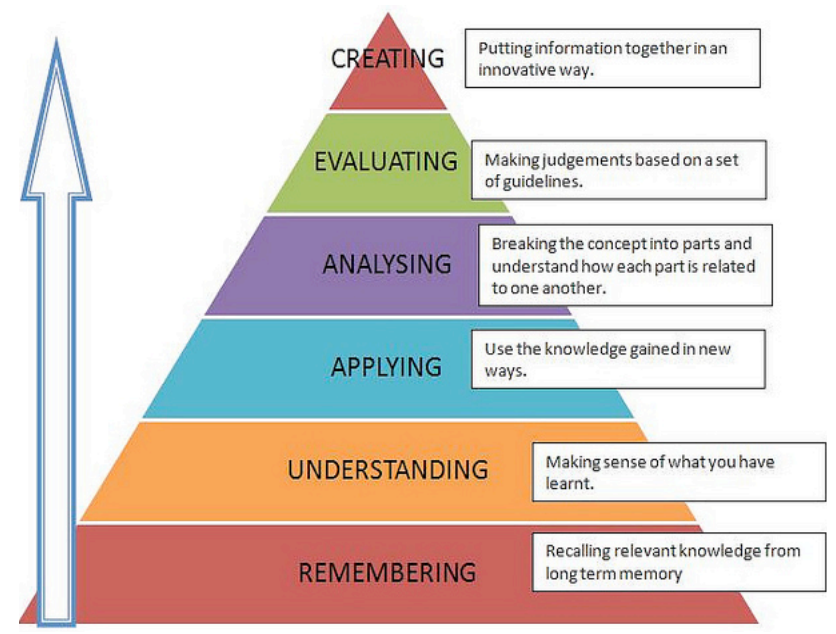

Figure 1. Bloom's revised taxonomy

This model is evidently applicable for higher education within the lecture-based courses but the question is how relevant it is to more communicative courses, namely, to foreign language teaching.

As we see it and have realized through the course of English for Engineering (blended model) at the Tomsk Polytechnic University [3], much of the ESL content can be flipped. This may include the delivery of some language material for further training in traditional class, online video or audio talks and podcasts for follow-up class discussion and analysis, explanations of grammar issues, instructions to different writing genres, pre-class glossary making etc. By putting a lot of course material online and employing the technology to help check and assess students' comprehension and progress, the language instructor is able to overcome the challenges that most educators face in the modern universities including 
reduction in contact hours, lack of students' motivation, shortage of teaching staff, etc.

\section{COURSE ORGANISATION}

The course of English for Engineering is intended for second-year undergraduates of the Tomsk Polytechnic University who major in Mechanical, Chemical, Optics and Biomedical Engineering within the Bachelor programmes presented in the Institute of High Technology Physics. Essentially, it is not a narrow-scoped ESP course; it is aimed at developing the students' professionallybiased communicative competence of English as well as introducing them to the main concepts and notions of engineering by means of English. The course syllabus includes such topics as general concepts and notions of engineering, introduction to Materials Science, advances in science and technology. The total number of contact hours is 64; the e-part of the course is used as a websupport with the elements of the blended learning model ( 8 contact hours are fully replaced by means of the online course in both synchronous and asynchronous modes; the other part is used as a support for the traditional classroom learning including the elements of the flipped or inverted classroom method). The course is delivered via the Moodle platform and employs the instruments which are compatible with this platform and/or can be integrated into the e-course.

While developing the course the authors took account of the following key elements of the flipped classroom as outlined by Brame C. (Vanderbilt University) [4]:

1. The course must provide an opportunity for students to gain first exposure prior to class. The mechanism used in our course varies from the PowerPoint presentations of the course material (e.g. introduction to Materials Science, information about the primary materials classification, etc.) to short Powtoon videos or podcasts. The basic language items are emphasized through highlighting or making them bold.

2. The course must provide an incentive for students to prepare for class. Talking about students one of the reliable and commonly accepted incentives is grading, i.e. earning points. The students are informed by the language instructor that the assignment that they will further do in the class grounds crucially on their preparation at home, thus, the result of it is dependable on how well they studied the material prior to the class. An additional way for motivating students can be the employment of either new engaging technologies (not monotonous texts delivered through the Moodle's Lecture tool or $p d f$ files) or truly interesting and even provocative resources (TED's talks, journal articles, etc.). Alternatively, students' preparation can also be graded through comprehension check tests, follow-up tasks, or forum discussions.

3. The course must provide a mechanism to assess student understanding. In our case, students are supposed to complete various pre-class online assignments such as simple comprehension check tests or quizzes (multiple choice questions, true/false statements, gap filling, etc.), written tasks (e.g. write your explanation/comments to the Figure presented on Slide 6), discuss an idea with their peers in the forum. Thus, we can help students focus their attention on the most important areas, clarify their thinking about the issues under discussion, train the usage of the necessary vocabulary and grammar items, prepare for more productive and in-depth classroom work.

4. The course must provide in-class activities that focus on higher level cognitive activities. The pre-class assignments are intended to ensure sufficient preparation for deeper and highly productive learning in class. In our case, the in-class activities are mostly directed at developing the students' communicative competence by making them participate in discussions, role-plays, simulating real-life communicative situations, case studying, etc. An example of the flipped model organization is as follows:

Step 1. Students study the material properties online (Powtoon video presentation with basic language in bold, links to supplementary materials, language training tasks). In addition, they can be asked to compile the glossary on the properties mentioned in the video.

Step 2. In a class the teacher checks students' overall comprehension by a short oral quiz (e.g. by demonstrating any material and asking students to enlist its main properties). There can also be a teacher-led discussion of the supplementary resources that the students have studied prior to the class.

Step 3. Students are organized into small groups and are given a case study task with the teacher's instructions (e.g. they come up against a problem of selecting a material for a purpose which is specified). Students discuss their solutions/proposals in the groups and, then, present their feedback to the class. The language instructor facilitates the process of group discussions, provides any language help, and assesses students' performance.

Step 4. The class discuss all the presented proposals and choose the most appropriate.

Step 5. Follow-up task. The students are asked to write a letter of proposal following the instructions presented in the online part of the course. Optionally, they can post their letters online (Forum or Seminar Moodle tool) and review their peers' works according to the assessment criteria outlined by the teacher.

Thus, students are firstly exposed to some basic theoretical material plus initial language use training via the e-course; then, they perform some higher level cognitive task with deeper analysis in a simulated real-life communicative situation within the classroom work.

\section{Flipped ClassRoom In ESL TeACHING: BenEFITS AND CHALLENGES}

There have been a number of studies emerging around the flipped classroom but most of them focus on the effectiveness of this approach for lecture-based courses. Among such research are the experiments conducted at the Villanova University [5], Harvey Mudd College [6], the University of British Columbia [7], the University of Malaya [8], etc. They have revealed different results with regard to the effectiveness of the flipped classroom model from being absolutely positive to indicating no difference in the learning outcomes compared to traditional classes. 


\section{SHORT PAPER \\ ANALYZING THE Potential OF FLIPPED ClassRoOM IN ESL TEACHING}

The experiment that was conducted at the Tomsk Polytechnic University during a semester in 2015 involving 4 groups of 42 students totally has indicated the following benefits of using the flipped model in ESL teaching:

1. Based on the students' feedback obtained via questionnaires and personal talks we can state that most students have positive perception towards the use of the flipped classroom in language teaching. They notice that this approach allows them to use their own learning styles and strategies when dealing with the course content before the class, and to use classroom time for more engaging and productive activities. Moreover, being able to work at their own pace and being exposed to a variety of supportive materials and instructions students with a lower level of English feel more confident and prepared when they come to the traditional class.

2. Regarding the learning gains, when compared to the controlled group (traditional instruction) the experiment group (flipped model) show 28\% higher results on the Final Objective Performance Test that included reading, listening, use of English, writing, and speaking tasks, which indicates a significant increase in students overall performance on the course.

3. An even more important outcome, probably, is that students notice that being exposed to the flipped classroom model and to blended learning in general, they have trained their autonomous learning skills and have acquired a more independent learning culture. Evidently, this statement needs further longtime observation and research to be verified by both quantitative and qualitative methods.

Needless to say, that the adoption of the flipped classroom model has enabled language instructors to compensate for the reduced contact hours of the English course as well as to make the learning process more studentcentered.

Meanwhile, it is necessary to outline the challenges that have been encountered while implementing the flipped model:

1. Although the current state of recording technology and web-based tools is commonly considered to be affordable and ubiquitous, the process of producing the learning content for the e-course can be timeconsuming and requires additional IT skills, knowledge, and an understanding of what these tools are from the instructor. Moreover, the ready-to-use course needs continuous "housework" as lots of weblinks and supportive materials get outdated or completely disappear on the Internet.

2. The learning content for the e-part of the course must be engaging to ensure the sustained motivation of students; the forms and tools for the material delivery should meet the students' needs and interests (videos rather than texts, thought-provocative talks, etc.). Differentiation in the students' learning styles and command of the language should also be taken into account.

3. Not all the ESL classes can be flipped. A language instructor must analyze the syllabus and choose the content/activities that are "flippable" and are better to be put online. At the same time, it is important that classroom time is given to higher-level activities such as debates, discussions, case studies, presentations, role plays, etc.

4. The role of an instructor in flipped classroom changes. Teachers are rather the facilitators in the learning process than the key sources of information for students. Nevertheless, the strict control and instruction of a teacher during the students' online preparation for the class has to be visible and felt by the students even if an e-course employs automated assessment tools. This can be realized through forums, teacher's comments, and work with the use of synchronous mode tools.

\section{CONCLUSION}

The use of the flipped classroom model for certain parts of the course syllabus throughout a semester has allowed a significant increase in students' performance on the course, enhancement of students' motivation and improvement of their autonomous learning skills. Thus, we can conclude that the examined approach can be applicable and is beneficial not only for lecture-based courses but for ESL teaching as well.

At the same time, to ensure progress, future research on the flipped classroom should be done to examine the consistency and sustainability of the obtained results. It might also be important to describe and analyze the existing tools, technologies that are mostly beneficial and less labour-consuming for effective language teaching.

\section{REFERENCES}

[1] Horizon Report for Higher Education in 2015. Retrieved 03.11.15 from http://cdn.nmc.org/media/2015-nmc-horizon-report-HEEN.pdf

[2] Retrieved 15.11.15 from CreativeCommons http://wilsonsflipped lab.blogspot.co.uk/2013/06/climbing-pyramid-blooms-with-flip.ht $\underline{\mathrm{ml}}$

[3] English for Engineering (blended course). http://stud.lms.tpu.ru/course/view.php?id=177http://stud.lms.tpu.r u/course/view.php?id=177

[4] Brame, C., (2013). Flipping the classroom. Retrieved 15.11.15 from http://cft.vanderbilt.edu/guides-sub-pages/flipping-the-class room

[5] Villanova: Improved student performance in 'flipped' classes. Retrieved 11.11.15 from http://articles.philly.com/2014-0928/news/54380476 1 lecture-classroom-engineering

[6] Han J. HMC Flipped Classroom Study Shows No Difference. Retrieved 30.10.2015 from http://tsl.news/articles/2014/10/3/ news/5494-hmc-flipped-classroom-study-shows-no-difference

[7] ETEC 522 - Flipped \& Blended Learning at http://etec522flipped.weebly.com.

[8] Zainuddin, Z., \& Attaran, M. (2015). Malaysian students' perceptions of flipped classroom: A case study. Innovations in Education and Teaching International, http://dx.doi.org/10.1080/147032 $\underline{97.2015 .1102079}$

\section{AUTHORS}

O. S. Kvashnina is with National Research Tomsk Polytechnic University, Tomsk, Russia (cuba@tpu.ru).

E.A. Martynko is with National Research Tomsk Polytechnic University, Tomsk, Russia (student) (ekaterina.martynko@gmail.com).

Submitted 25 November 2015. Published as resubmitted by the authors 26 February 2016. 